\title{
Contraception in Canada: a review of method choices, characteristics, adherence and approaches to counselling
}

\author{
William A. Fisher, Amanda Black
}

\section{ABSTRACT}

Contraception is a significant concern for Canadian women of child-bearing age, their partners and their health care providers. In this narrative review we provide information on current trends and recent changes in Canadians' choices of contraceptive methods. We review the characteristics of contraceptive methods available in Canada, with an emphasis on hormonal methods and newer options such as the transdermal contraceptive patch, the vaginal contraceptive ring and the levonorgestrel-releasing intrauterine system. We also discuss adherence to contraception as well as approaches to counselling to promote adherence and to reduce the risk of sexually transmitted infections in the context of contraception.

$C M A J 2007 ; 176(7): 953-6$ I

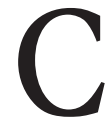

ontraception is a significant concern for Canadian women of child-bearing age, their partners and their health care providers. ${ }^{1-9}$ In this narrative review we provide information on Canadians' contraceptive choices and on the characteristics of major contraceptive methods, including several newer methods. We also discuss adherence to contraception and approaches to counselling to promote adherence and to reduce the risk of sexually transmitted infections in the context of contraception.

\section{Trends in use}

Canadian Contraception Studies, ${ }^{4-9}$ conducted in 1993, I995, 1998 and 2002 with nationally representative samples of women, have provided information about Canadians' choices of contraceptive methods. According to the 2002 report, among respondents aged $15-44$ years, oral contraception, condoms and sterilization were the contraceptive methods of choice. Oral contraception and condoms were the predominant methods reported by unmarried women aged $15-17$. Sterilization was the predominant method among married couples aged 35-44, with male sterilization more than twice as common as female sterilization.

The Canadian Contraception Studies ${ }^{8,9}$ also explored reasons for Canadians' choices of contraceptive methods. Respondents who used oral contraception reported choosing this method on the basis of its effectiveness, ease of use and recommendation by their health care provider. Those who used condoms reported choosing this method because of its lack of side effects, ease of use, use only when needed and effectiveness. Only $7 \%$ of the condom users indicated that they chose this method primarily for protection against sexually transmitted infections. Findings from these surveys ${ }^{8,9}$ also indicate that the majority of respondents currently using contraception were satisfied with their chosen method.

Because similar survey questions and sampling approaches were used for every Canadian Contraception Study, ${ }^{4-9}$ we are able to describe trends in the choice of contraceptive methods from 1993 to 2002 among Canadians aged 15-44 years. Use of oral contraceptives was steady during this period ( $27 \%$ in 1993 , $28 \%$ in 2002) and remained the most commonly chosen method of reversible contraception. Condom use steadily declined, from a peak of $25 \%$ in 1995 to a decade low of $18 \%$ in 2002. This decline in condom use was paralleled by recent increases in gonorrhea and syphilis, ${ }^{10}$ and in HIV infection among women. ${ }^{11}$ Contributing factors may have included "safer sex fatigue" and the belief that HIV infection is now a manageable disease, ${ }^{12}$ the fact that condom use can stop following prescription of oral contraceptives ${ }^{13}$ and the fact that condom use is uncommon within what individuals perceive to be a relationship. ${ }^{14}$ The frequency of male sterilization remained constant ( $14 \%$ in $1993,13 \%$ in 2002); however, female sterilization experienced the most dramatic drop in prevalence of any contraceptive method during this time ( $16 \%$ in $1993,7 \%$ in 2002). Use of intrauterine devices remained very low ( $\mathrm{r} \%$ in 1993, $\mathrm{I} \%$ in 2002). These findings of the predominance of oral contraception, condoms and sterilization reflect the narrow range of contraceptive method choices made by Canadians.

\section{Contraceptive options}

A number of contraceptive options are available to Canadians (Table I). Hormonal contraception, intrauterine devices and systems, and emergency contraception are addressed in more detail in the following section. Health care providers should work with their patients to determine which method would be most appropriate for each individual, acknowledging both medical issues and issues of adherence and safer sex.

\section{Combined hormonal contraception}

Combined hormonal methods contain estrogen and progestin and include oral contraceptives, the transdermal contraceptive patch and the vaginal contraceptive ring. 


\section{Oral contraception}

Oral contraceptives are highly effective and may be considered, in the absence of contraindications (Box I), for women seeking a reliable, reversible method of contraception. They also have a number of noncontraceptive benefits that may make them a desirable option. ${ }^{2}$ Side effects are usually minor and diminish after the first 3 cycles of use. ${ }^{16}$ Studies have not shown an association between use of a low-dose oral contraceptive (20-35 $\mu \mathrm{g}$ ethinyl estradiol per day) and weight gain ${ }^{22}$ or mood changes. ${ }^{43}$ Risks associated with oral contraceptive use include venous thromboembolism (3- to 4-fold increased risk compared with nonuse). ${ }^{17,18} \mathrm{~A}$ significant pharmacokinetic interaction between oral contraceptives and antibiotics other than rifampin and griseofulvin has not been found. ${ }^{2}$

Traditional methods to start taking oral contraceptives (e.g., first-day start [on the first day of menses] or Sunday start) may be used. The "quick-start" method, whereby the woman takes her first pill on the day of her office visit, provided she is not pregnant, may also be used. A back-up method of contraception is required for the first 7 days. The quick-start method has been found to increase adherence, with no associated increase in breakthrough bleeding or other side effects. ${ }^{44,45}$ A pelvic examination is not a prerequisite to providing hormonal contraception. ${ }^{2,46}$

Women may choose to take oral contraception in an extended or continuous fashion, with no 7-day pill-free interval. Continuous use for several cycles without periodic withdrawal bleeding may be considered for women who have symptoms during the pill-free interval (e.g., pelvic pain, headaches, menstrual migraines) or who have dysmenorrhea or menorrhagia. Breakthrough bleeding with extended or continuous regimens typically decreases with time. ${ }^{47}$ Women who have breakthrough bleeding while taking an extended regimen may manage this by continuing to take the pill or they may stop the pill for $3-7$ days and then resume taking it. ${ }^{48}$ At no time should the pill-free interval exceed 7 days. The longest follow-up study of an extended or continuous regimen included 189 women in an open-label observational study in which all patients received an extended 9Iday cycle regimen for 2 years. ${ }^{49} \mathrm{~A}$ Cochrane review of 6 randomized controlled trials concluded that continuous and traditional regimens had similar rates of bleeding, discontinuation and reported satisfaction; however, the included trials were too small to address efficacy, rare adverse events and long-term safety. ${ }^{50}$ Although continuous or extended regimens appear to be a reasonable approach to oral contraception and may in some cases be beneficial, health care providers should inform their patients of the limited evidence regarding long-term risks of therapy.

\section{Transdermal contraceptive patch}

The transdermal contraceptive patch (Evra) is an effective method of reversible contraception whose mechanism of action is similar to that of oral contraceptives (Table I). The patch's once-a-week dosing schedule may help with adherence. ${ }^{2}$ Limited evidence suggests that the effectiveness of the patch may decline for women weighing $90 \mathrm{~kg}$ or more. ${ }^{23}$ Pending further evidence, contraindications for using the patch are the same as those for oral contraceptives. No studies have examined whether avoidance of the first-pass effect of hormones on the liver with use of the patch lessens concerns about drug interactions or about use of the patch for women with liver conditions. Studies have shown increased serum total cholesterol and triglyceride levels in both patch and oral contraceptive users; ${ }^{23}$ however, the increases are typically not clinically significant.

Side effects and risks associated with use of the contraceptive patch are similar to those experienced by oral contraceptive users. Although patch users have been reported to have significantly higher rates of spotting in cycles I and 2, cycle control is otherwise comparable to that with oral contraceptives. ${ }^{23}$ Breast symptoms and headache are the most common side effects reported by patch users, with rates of breast symptoms in the first 2 cycles being higher among patch users than among oral contraceptive users. ${ }^{23}$ Local reactions at the application site may occur in up to $20 \%$ of patients, but only $2 \%$ of users have reportedly discontinued use of the patch for this reason. ${ }^{23}$

Concerns have been raised that the contraceptive patch exposes users to more estrogen than a $35-\mu \mathrm{g}$ oral contraceptive pill and thus may theoretically increase the risk of estrogenrelated adverse events. Users of the patch are exposed to $60 \%$ more estrogen overall than oral contraceptive users, but the peak blood level of ethinyl estradiol is higher with the oral contraceptive than with the patch. ${ }^{51}$ It is unknown whether this additional estrogen exposure causes additional harm, such as blood clots. The Canadian version of the patch contains less ethinyl estradiol than the version sold in the United States (o.6o mg v. $0.75 \mathrm{mg}$ ), and the total estrogen exposure with the Canadian version appears to be closer to that of a $35-\mu$ g pill. ${ }^{52}$

When initiating the patch, the first-day start method (first day of menses) is recommended, although the quick-start method (at the physician's office) can also be used. A new patch is applied weekly for 3 weeks on the "patch change day," and a fourth week is patch-free, during which withdrawal bleeding occurs. The patch has also been used continuously, with no patch-free week, with high rates of patient satisfaction..$^{53}$

Patch detachment is uncommon. Should the patch become detached for less than 24 hours, the woman should attempt to reapply it and, if unsuccessful, apply a new patch. If detachment has occurred for more than 24 hours, a new patch should be applied and back-up contraception should be used for 7 days. If the woman is late in changing her patch by less than 48 hours, she should change it immediately. If she waits more than 48 hours, a new 4-week cycle should be started by applying a new patch and back-up contraception should be used for 7 days.

\section{Vaginal contraceptive ring}

The vaginal contraceptive ring (NuvaRing) is a $54-\mathrm{mm}$ ring made of an ethylene vinyl acetate copolymer that releases a constant dose of $15 \mu \mathrm{g}$ of ethinyl estradiol and $0.120 \mathrm{mg}$ of etonorgestrel per day (Table I). Hormone levels needed to suppress ovulation are achieved within the first day of use. Each ring is used for I cycle and then removed. A cycle consists of 3 weeks of continuous use of the ring followed by a Iweek ring-free interval of no longer than 7 days. Extended or continuous use of the ring (less frequent or no ring-free inter- 
Table 1: Characteristics, effectiveness, advantages, side effects and risks of selected methods of contraception ${ }^{1-3,15}$

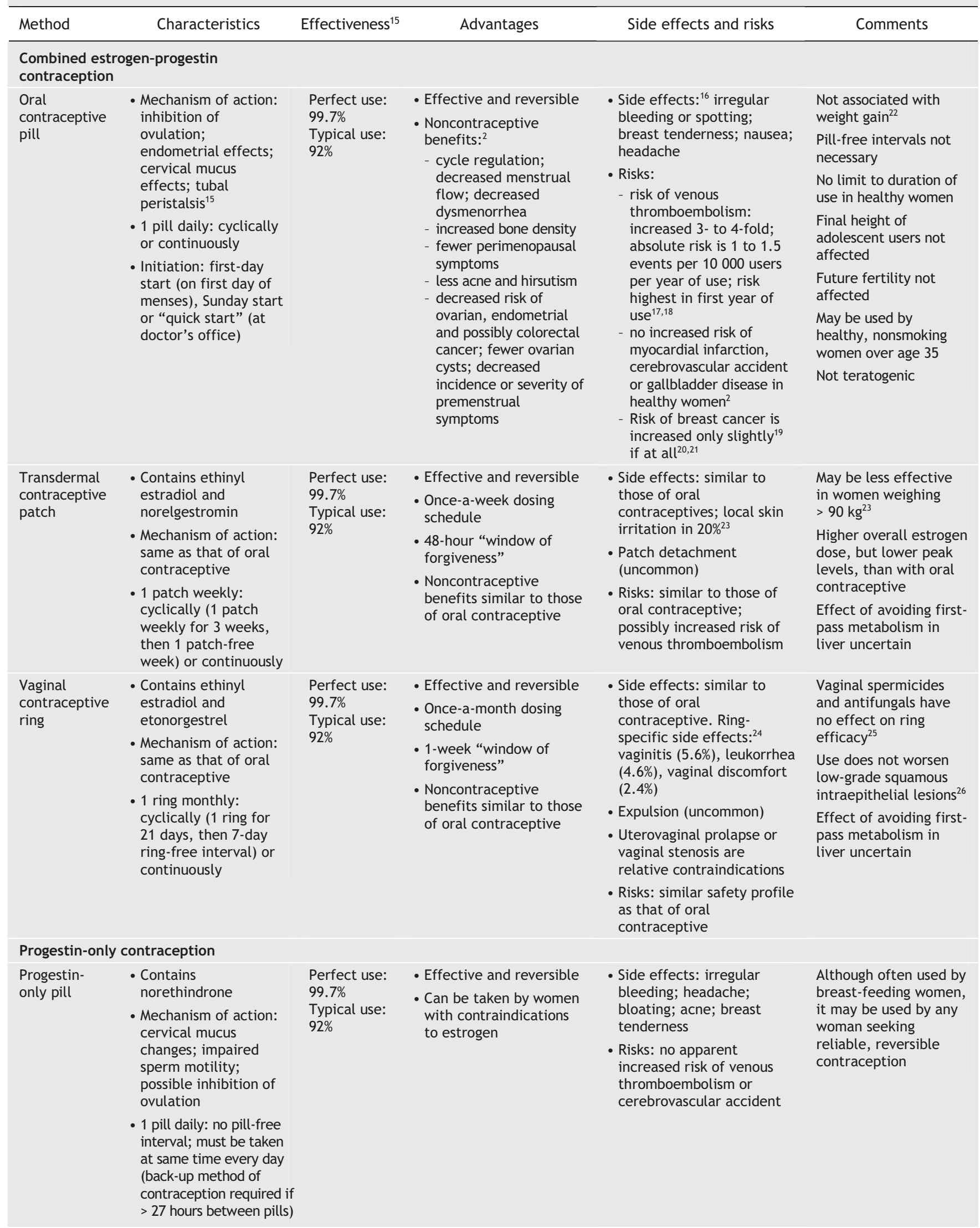


Table 1 continued

\begin{tabular}{|c|c|c|c|c|c|}
\hline Method & Characteristics & Effectiveness $^{15}$ & Advantages & Side effects and risks & Comments \\
\hline Male condom & $\begin{array}{l}\text { Latex or non-latex } \\
\text { sheath used over the } \\
\text { penis during } \\
\text { intercourse }\end{array}$ & $\begin{array}{l}\text { Perfect use: } \\
98 \% \\
\text { Typical use: } \\
85 \%\end{array}$ & $\begin{array}{l}\text { - Effective if used } \\
\text { consistently and } \\
\text { correctly } \\
\text { - No prescription required } \\
\text { - Protects against many } \\
\text { sexually transmitted } \\
\text { infections } \\
\text { - May reduce premature } \\
\text { ejaculation }\end{array}$ & & $\begin{array}{l}\text { For women or men with } \\
\text { latex allergy, non-latex } \\
\text { condoms are available } \\
\text { (polyurethane and } \\
\text { natural lambskin) } \\
\text { Natural-membrane } \\
\text { condoms do not prevent } \\
\text { sexually transmitted } \\
\text { infections as effectively } \\
\text { as other condoms }\end{array}$ \\
\hline $\begin{array}{l}\text { Female } \\
\text { condom }\end{array}$ & $\begin{array}{l}\text { Polyurethane sheath } \\
\text { inserted into the } \\
\text { vagina before } \\
\text { intercourse; can be } \\
\text { placed up to } 8 \text { hours } \\
\text { before intercourse }\end{array}$ & $\begin{array}{l}\text { Perfect use: } \\
\text { 95\% } \\
\text { Typical use: } \\
79 \%\end{array}$ & $\begin{array}{l}\text { - Effective if used } \\
\text { consistently and } \\
\text { correctly } \\
\text { - No prescription required } \\
\text { - Protects against many } \\
\text { sexually transmitted } \\
\text { infections } \\
\text { - Female controlled }\end{array}$ & $\begin{array}{l}\text { - Can be noisy during } \\
\text { intercourse } \\
\text { - Some users find it difficult } \\
\text { to insert } \\
\text { - The inner ring may cause } \\
\text { discomfort during } \\
\text { intercourse }\end{array}$ & $\begin{array}{l}\text { Should not be used at } \\
\text { the same time as a } \\
\text { male condom }\end{array}$ \\
\hline Diaphragm & $\begin{array}{l}\text { - Dome-shaped latex cup } \\
\text { (silicone diaphragms } \\
\text { also available) that } \\
\text { covers the cervix; } \\
\text { inserted into the vagina } \\
\text { up to } 6 \text { hours before } \\
\text { intercourse } \\
\text { - Must be left in the } \\
\text { vagina for at least } \\
6 \text { hours, but no more } \\
\text { than } 24 \text { hours, after } \\
\text { intercourse } \\
\text { - Used with a } \\
\text { spermicide } \\
\text { - Must be fitted by a } \\
\text { health care provider }\end{array}$ & $\begin{array}{l}\text { Perfect use: } \\
\text { 94\% } \\
\text { Typical use: } \\
84 \%\end{array}$ & $\begin{array}{l}\text { - Nonhormonal } \\
\text { - Some protection against } \\
\text { sexually transmitted } \\
\text { infections } \\
\text { - Can be used during } \\
\text { menses }\end{array}$ & $\begin{array}{l}\text { - Some women find correct } \\
\text { insertion difficult } \\
\text { - Possible sensitivity to } \\
\text { latex or spermicide } \\
\text { - May increase risk of } \\
\text { persistent urinary tract } \\
\text { infection } \\
\text { - Does not protect against } \\
\text { HIV infection } \\
\text { - Wearing diaphragm } \\
>24 \text { hours may increase } \\
\text { risk of toxic shock } \\
\text { syndrome }\end{array}$ & $\begin{array}{l}\text { Should not be used } \\
\text { with oil-based } \\
\text { lubricants or } \\
\text { medications }\end{array}$ \\
\hline
\end{tabular}

val) is associated with fewer bleeding days but more spotting days than that associated with the 28 -day cycle. ${ }^{54}$

The ring can be considered for women seeking a reliable reversible method of contraception. Its once monthly dosing schedule may cause fewer adherence problems than other methods. Pending further evidence, absolute contraindications are similar to those for oral contraceptives. Uterovaginal prolapse or vaginal stenosis may be considered relative contraindications if they prevent retention of the ring. To date, no studies have examined whether avoidance of the first-pass effect of hormones on the liver with ring use lessens concerns about drug interactions or about ring use among women with liver conditions. Neither vaginal spermicides nor vaginal miconazole has an effect on ring efficacy. ${ }^{25}$

Hormonal side effects of the vaginal contraceptive ring are similar to those of oral contraceptives. Other side effects specific to the ring include vaginitis $(5.6 \%)$, leukorrhea (4.6\%) and vaginal discomfort (2.4\%). ${ }^{24}$ According to available evidence, the ring provides a comparable safety profile to that of oral contraceptives with similar hormone formulations. Evidence suggests that the ring does not alter vaginal flora, ${ }^{26}$ and limited evidence from studies involving women with lowgrade squamous intraepithelial lesions found that use of the ring did not worsen the condition. ${ }^{26}$ 
Expulsion of the ring is rare. If it occurs and the ring has been out of the vagina for less than 3 hours, the ring should be rinsed in lukewarm water and reinserted. If the ring has been out of the vagina for more than 3 hours, the ring should be rinsed in lukewarm water and reinserted, and a back-up method of contraception should be used for 7 days. If the ring remains in the vagina for more than 3 weeks but less than 4 weeks, it is still effective in preventing pregnancy. It should be removed and a new ring inserted after a I-week ring-free interval. If the ring has been in place for more than 4 weeks, it may no longer provide adequate protection against pregnancy. Emergency contraception should be considered and a back-up method of contraception used until a new ring has been in place for at least 7 days. $^{2}$

\section{Progestin-only contraception}

Progestin-only contraception is available in Canada in the form of injectable depot medroxyprogesterone acetate (Depo-

Box 1: Absolute contraindications to contraceptive methods ${ }^{42}$

Oral contraceptive pill

- $<6$ weeks postpartum if breast-feeding

- Hypertension (systolic blood pressure $>160 \mathrm{~mm} \mathrm{Hg}$ or diastolic > $100 \mathrm{~mm} \mathrm{Hg}$ )

- Venous thromboembolism (current or past)

- Ischemic heart disease

- History of cerebrovascular accident

- Complicated valvular heart disease

- Migraine headache with focal neurologic symptoms

- Migraine headache without aura in woman over age 35

- Breast cancer (current)

- Diabetes with end-organ involvement

- Severe cirrhosis

- Liver tumour

- Active viral hepatitis

- Woman over age 35 who smokes (> 15 cigarettes/day)

- Known thrombogenic mutation (factor V Leiden; prothrombin mutation; or protein $\mathrm{C}$, protein $\mathrm{S}$ or antithrombin III deficiency)

Depot medroxyprogesterone acetate

- Breast cancer (current)

- Pregnancy

Intrauterine device/system

- Pregnancy

- Current, recurrent or recent (within 3 months) sexually transmitted infection or pelvic inflammatory disease

- Puerperal sepsis

- Immediate post-septic abortion

- Severely distorted uterine cavity

- Unexplained vaginal bleeding

- Cervical or endometrial cancer (awaiting treatment)

- Malignant trophoblastic disease

- Breast cancer (current) - for levonorgestrel-releasing intrauterine system

- Copper allergy - for copper intrauterine device
Provera) and in oral form (Micronor). The 6-rod implant system (Norplant) is no longer available.

Depot medroxyprogesterone acetate is highly effective and has a number of advantages. It does not contain estrogen, which may make it suitable for women who have absolute or relative contraindications to estrogen use (e.g., those with thrombophilias or who are smokers over the age of 35 , those with hypertension and those who experience migraines with associated neurologic symptoms). ${ }^{2}$ This injectable form of progestin has also been used to treat menorrhagia, dysmenorrhea, endometriosis and chronic pelvic pain. Women who prefer not to have menses may benefit from the associated amenorrhea, which occurs in $55 \%-60 \%$ of users at I2 months. Depot medroxyprogesterone acetate may also pose fewer adherence problems than other forms of contraception because it is given as an intramuscular injection every I2 to I 3 weeks. Frequently reported side effects include menstrual cycle disturbances, headache, weight changes and mood effects. ${ }^{2}$ Although depot medroxyprogesterone acetate is a reversible method of contraception, return of fertility may be delayed for 9 months on average.

Strategies for the management of menstrual cycle disturbances include increasing the dose of depot medroxyprogesterone acetate for 2-3 injections, decreasing the dosing interval, prescribing supplemental estrogen therapy for I month, administering a nonsteroidal anti-inflammatory drug (ibuprofen $400-$ $800 \mathrm{mg}$ twice daily for to days, repeat once if necessary) or prescribing an oral contraceptive for $\mathrm{I}-3$ months. ${ }^{2}$ Women who are late for their injection may still receive their next injection provided that it has been less than I4 weeks since the last one. If it has been I4 or more weeks since the last injection, but the woman has not had intercourse within the last ro days and her serum pregnancy test result is negative, the injection can be given. She should be advised to use a back-up method of contraception for 2 weeks. If the woman has had intercourse within the last ro days, the injection can still be given if the pregnancy test result is negative; however, the woman will need to use a back-up method of contraception and have another pregnancy test in 2 weeks. ${ }^{2}$ Depot medroxyprogesterone acetate is not teratogenic if given inadvertently during pregnancy.

A potential long-term consideration for users of depot medroxyprogesterone acetate is whether their risk of fracture is increased because of reduced bone mineral density. ${ }^{27-29}$ The greatest reduction in bone mineral density occurs during the first 2 years of use of this contraceptive method; ${ }^{27}$ however, studies have shown substantial recovery of bone mineral density once use is stopped. ${ }^{27,30}$ Interim results from clinical studies prompted the US Food and Drug Administration to issue a "black box warning" for depot medroxyprogesterone acetate in $2004^{31}$ and Health Canada to issue an advisory in 2005. ${ }^{32}$ Interim analysis found that adult women who used depot medroxyprogesterone acetate for 5 years had a decrease of $5 \%-6 \%$ in hip and spine bone mineral density. The decline was most pronounced in the first 2 years of use. Partial but not complete recovery of bone mineral density occurred in the 2 years after discontinuation. Changes in bone mineral density associated with use of depot medroxyprogesterone acetate may be particularly important for adolescents, who have not yet attained their peak bone mass. It is unclear whether this loss prevents them from attaining their po- 
tential ultimate peak bone mass, or whether it will increase the risk of osteoporosis and fracture later in life.

The critical outcome with regard to bone health is the occurrence of fracture. ${ }^{33}$ It is not known whether the loss of bone mineral density due to the use of depot medroxyprogesterone acetate places women at increased risk of postmenopausal fracture. Available data do not support routine bone mineral density testing in users of this form of contraception; however, such testing may be appropriate for users with other significant risk factors for osteoporosis. Women using depot medroxyprogesterone acetate should be counselled on aspects of bone health, including calcium and vitamin D supplementation, weight-bearing exercise, decreased caffeine and alcohol intake, and smoking cessation. Supplemental estrogen therapy may attenuate the negative effects of depot medroxyprogesterone acetate on bone mineral density, but there are insufficient data to recommend its routine use. ${ }^{34}$

\section{Intrauterine devices and systems}

Two types of intrauterine devices and systems are currently available in Canada: copper intrauterine devices (Nova-T or Flexi-T 300) and a levonorgestrel-releasing intrauterine system (Mirena). Intrauterine devices and systems have multiple mechanisms of action, but the chief one appears to be prevention of fertilization (Table $\mathrm{I}) .{ }^{35}$ Both types are highly effective for up to 5 years. In the absence of contraindications, an intrauterine device or system can be considered for any woman seeking a reliable reversible method of contraception. This method is particularly suited for women who would like long-term birth control, who want a method that is easy to adhere to or who have contraindications to estrogen use. Nulliparity is not a contraindication to use. ${ }^{40}$

Intrauterine devices and systems provide a number of noncontraceptive benefits. Copper devices may decrease the risk of endometrial cancer, ${ }^{37}$ and the levonorgestrel-releasing intrauterine system is associated with improvement in menorrhagia and dysmenorrhea and may protect against endometrial hyperplasia. ${ }^{41}$ A significant proportion of women who use the levonorgestrel-releasing intrauterine system will experience a decrease in menstrual blood loss (reduction of between $74 \%$ and $97 \%$ ) or amenorrhea.

Bleeding irregularities are the most common side effects, particularly in the first months after insertion of the intrauterine device or system. Other potential side effects include pain or dysmenorrhea, hormonal side effects associated with the levonorgestrel-releasing intrauterine system (despite the fact that systemic levels of levonorgestrel are extremely $l o w^{36}$ ), and functional cysts, reported in up to $30 \%$ of women who use the levonorgestrel-releasing intrauterine system.

Risks associated with insertion include perforation ( 0.6 to I. 6 per 1000 insertions), expulsion ( $2 \%-10 \%$ in the first year of use $)^{36}$ and infection. There is an inverse relation between risk of infection and time since insertion; risk of infection is highest in the 20 days following insertion and then decreases to baseline. ${ }^{38}$ Large trials have shown that any risk of infection after the first month of use, when the relative risk of pelvic inflammatory disease is 3.8 , is small and similar to that in the general population. ${ }^{39}$ Exposure to sexually transmitted infections, not the intrauterine device or system itself, is responsible for the occurrence of pelvic inflammatory disease after the first month of use. Intrauterine devices and systems do not increase the risk of ectopic pregnancy, ${ }^{36}$ although if a pregnancy does occur with an intrauterine device or system in situ, ectopic pregnancy should be ruled out.

Intrauterine devices and systems can be inserted at any time during the menstrual cycle once the possibility of pregnancy is excluded. There is no evidence to support the practice of insertion only during menses. Antibiotic prophylaxis before insertion is not beneficial. ${ }^{55}$

\section{Emergency contraception}

Emergency contraception may be considered for any woman who wishes to avoid pregnancy after unprotected intercourse. This may include instances when no contraception was used or the contraceptive method failed, or sexual assault. Types of emergency contraception include hormonal methods (Yuzpe method and Plan B) and the copper intrauterine device. Plan B is available in Canada from pharmacists without a prescription. Although it is generally recommended that hormonal emergency contraception be taken within 72 hours after unprotected intercourse, it can in fact be taken up to 5 days afterward ${ }^{56,57}$ whereas a copper intrauterine device can be inserted up to 7 days afterward. Hormonal emergency contraception is usually taken in 2 doses, I2 hours apart, although Plan B is as effective if both tablets are taken at the same time. ${ }^{58,59}$ Hormonal methods may reduce the risk of pregnancy by $75 \%-$ $85 \%$ and are more effective the sooner they are taken.

Emergency contraception has several potential mechanisms of action. It may interfere with follicular development, cervical mucus, sperm migration, corpus luteum activity and fertilization. ${ }^{60}$ It has no effect on an established pregnancy. Women who use emergency contraception should be advised to have a pregnancy test if they do not experience normal menstrual bleeding by 2I days after treatment. Testing for sexually transmitted infections should also be considered.

\section{Adherence to contraception, counselling and safer sex}

Use of contraception is the end result of a person's performance of a complicated sequence of cognitive and behavioural steps. ${ }^{61}$ For a person to initiate and maintain contraception, he or she will have to acquire relevant information about contraception; acknowledge the probability of future sexual activity; take public actions to acquire contraceptives; communicate with his or her partner about contraception; use the contraceptive method consistently over time; and make accurate judgments about the need to practise safer sex. Whether this person will successfully navigate this sequence of steps depends on environmental factors (e.g., cost and availability of contraception and medical services, voluntary or involuntary nature of sexual activity) and personal factors (e.g., the person's age, sex and marital status) and is heavily influenced by the person's level of knowledge of contra- 
ception and his or her motivation and skill for performing the sequence of contraceptive behaviours in question. ${ }^{61}$ Viewed from this perspective, the health care provider's advice to "use contraception" actually places heavy demands on a patient's knowledge of contraception, motivation and behavioural skills.

As a result of the complexity of contraceptive behaviour ${ }^{61}$ and additional factors as simple as forgetting, Canadian's adherence to contraceptive methods is far from perfect. About $9 \%$ of Canadians who responded to a study on contraception ${ }^{8,9}$ indicated that they use no method of contraception, despite the lack of desire to conceive. Adherence problems with chosen methods were also common: $62 \%$ of the respondents who identified themselves as current oral contraceptive users reported having missed at least one pill during the 6 months before the survey; $3 \mathrm{I} \%$ of these respondents missed $\mathrm{I}$ or 2 pills, and $\mathrm{I} \%$ missed 6

Box 2: Approaches to counselling patients about adherence to contraception and practice of safer sex ${ }^{62-64}$

To clarify and strengthen the importance of adhering to contraception and practising safer sex, the physician asks:

Question 1: "On a scale of 1 to 10 , how important is it to you to ...?" [“... take the pill as prescribed, each and every day?"] or ["... see to it that you and your partner always use condoms?"]

- If the patient responds with a score of 7 or less, ask: "Why did you say [score] and not lower?" (This paradoxical question challenges patients to come up with personally convincing reasons why it is important to adhere to contraception or to practise safer sex.)

- If the patient responds with a score of 8 or higher, proceed to question 3.

Question 2: "What would it take [or What would have to happen] for it to become more important to you to ...?" [“... take the pill as prescribed, each and every day?"] or [“... see to it that you and your partner always use condoms?"]

- Patients know best what it would take to change their opinion, and they will tell the clinician what it would take to make adherence or safer sex more important to them personally. Physician and patient can discuss these responses.

To clarify and strengthen the ability to adhere to contraception and to practise safer sex, the physician asks:

Question 3: "On a scale of 1 to 10, how confident are you that you could ...?" ["... take the pill as prescribed, each and every day?"] or ["... see to it that you and your partner always use condoms?"]

- If the patient responds with a score of 7 or less, ask: "Why did you say [score] and not lower?" (This paradoxical question prompts patients to think about their strengths in managing adherence or practising safer sex.)

- If the patient responds with a score of 8 or higher, explore possible barriers that could occur and how the patient might deal with them.

Question 4: "What would it take [or What would have to happen) for you to become more confident that you could ...?" [“... take the pill as prescribed, each and every day?"] or [“.... see to it that you and your partner always use condoms?"]

- Patients again know best what it would take to change their behaviour, and they will tell the clinician what it would take to do so. Patient and physician can use this as a context for problem-solving around adherence and safer sex. or more pills during this time. ${ }^{8,9}$ Similarly, $30 \%$ of the respondents who reported using condoms indicated that they did not always use a condom during sexual intercourse in the 6 months before the survey. Perhaps not surprisingly, some $28 \%$ of the female respondents reported having experienced an unplanned pregnancy. ${ }^{8,9}$ On the basis of these findings, it appears that adherence to a contraceptive method and not the choice of method per se may be the more challenging goal for clinical counselling and patient practice. Box 2 presents empirically validated counselling techniques ${ }^{62-64}$ that may be effective in challenging situations in which patients have particular difficulties adhering to their chosen method of contraception.

The use of contraception and its relation to safer sex and risky sexual behaviour presents an additional clinical concern. There is an association between the use of oral contraceptives, cessation or nonuse of barrier methods, and increased risk of sexually transmitted infection. ${ }^{13,14}$ The primary concern of sexually active people is often avoidance of pregnancy. Once a nonbarrier contraceptive method has been prescribed, the health care provider may have inadvertently eliminated this primary concern of the patient's and increased his or her risk of sexually transmitted infection. ${ }^{13,14}$ Counselling strategies ${ }^{9}$ for enhancing condom use when providing nonbarrier contraception include suggesting scripts for safer sexual behaviour such as "Always use condoms together with the pill for 3 months, then come in with your partner for STI/HIV testing and safer sex counselling."

\section{Summary}

We have reviewed evidence concerning Canadian's contraceptive choices, the characteristics and controversies associated with familiar and with newer contraceptive methods, and findings for inconsistent adherence and risk of sexually transmitted infection in the context of contraception. Method choice, management and counselling strategies are suggested to assist the physician in addressing these important challenges in contraceptive practice in Canada.

This article has been peer reviewed.

From the Departments of Psychology and of Obstetrics and Gynaecology (Fisher), University of Western Ontario, London, Ont., and the Department of Obstetrics and Gynaecology (Black), University of Ottawa, Ottawa, Ont.

Competing interests: William Fisher received speaker fees and travel assistance from Janssen-Ortho to present a talk at the 2006 Society of Obstetrics and Gynaecology of Canada annual meeting and speaker fees from Wyeth-Ayerst to support a presentation at a continuing medical education engagement in 2006. He received a Janssen-Ortho Research Scientist Award in 2005 for his work in the Department of Obstetrics and Gynaecology, University of Western Ontario. Amanda Black received honoraria for continuing medical education speaking engagements from Janssen-Ortho, Organon and Wyeth-Ayerst.

Contributors: William Fisher and Amanda Black jointly carried out the literature review, writing and multiple revisions of this article. Both authors approved the final version accepted for publication.

\section{REFERENCES}

I. Black A, Francoeur D, Rowe T. SOGC clinical practice guidelines: Canadian contraception consensus. Part I. J Obstet Gynaecol Can 2004;26:I43-56.

2. Black A, Francoeur D, Rowe T. SOGC clinical practice guidelines: Canadian contraception consensus. Part 2. JObstet Gynaecol Can 2004;26:219-96. 
3. Black A, Francoeur D, Rowe T, et al. SOGC clinical practice guidelines: Canadian contraception consensus. Part 3. JObstet Gynaecol Can 2004;26:347-87.

4. Boroditsky R, Fisher WA, Sand M. The Canadian contraception study. JObstet Gynaecol Can I995; 17 (Suppl):Si-28.

5. Boroditsky R, Fisher WA, Sand M. The 1995 Canadian contraception study. J Obstet Gynaecol Can 1996;18(Suppl):SI-3I.

6. Fisher WA, Boroditsky R, Bridges M. The 1998 Canadian contraception study. Can JHum Sex 1999;8:16I-2I6.

7. Fisher WA, Boroditsky R. Sexual activity, contraceptive choice, and sexual and reproductive health indicators among single Canadian women aged I5-29: additional findings from the Canadian contraception study. Can J Hum Sex 1999;2:79-93.

8. Fisher WA, Boroditsky R, Morris B. The 2002 Canadian contraception study: Part I. JObstet Gynaecol Can 2004;26:580-90.

9. Fisher WA, Boroditsky R, Morris B. The 2002 Canadian contraception study: Part 2. JObstet Gynaecol Can 2004;26:646-56.

Io. Public Health Agency of Canada. 2004 Canadian sexually transmitted infections surveillance report: pre-release. Ottawa: The Agency; 2004. Available: www.phac-aspc .gc.ca/std-mts/stddata_preo6_04/index.html (accessed 2006 Dec I2).

II. Public Health Agency of Canada. HIV and AIDS in Canada. Surveillance report to December 3I, 2005. Ottawa: The Agency; 2006. Available: www.phac-aspc.gc.ca /publicat/aids-sida/haic-vsacı205/pdf/haic-vsaci205.pdf (accessed 2006 Dec I2).

I2. Ostrow DE, Fox KJ, Chimel JS, et al. Attitudes towards highly active antiretroviral therapy are associated with sexual risk taking among HIV-infected and uninfected homosexual men. AIDS 2002;16:775-80.

13. MacDonald NE, Wells GA, Fisher WA, et al. High risk STD/HIV behavior among college students. JAMA I990;263:3155-9.

I4. Misovich SJ, Fisher JD, Fisher WA. Close relationships and HIV risk behavior: evidence and possible underlying psychological processes. Gen Psychology Rev 1997;1:72-107.

I5. Hatcher RA, Trussell J, Stewart F, et al. Contraceptive technology. I8th ed. New York: Ardent Media; 2004

I6. Rosenberg MJ, Meyers A, Roy V. Efficacy, cycle control, and side effects of low- and lower-dose oral contraceptives: a randomized trial of 20 micrograms and $35 \mathrm{mi}-$ crograms estrogen preparations. Contraception I999;60:32I-9.

I7. Vandenbroucke JP, Rosing J, Bloemenkamp KW, et al. Oral contraceptives and the risk of venous thrombosis. N Engl J Med 200I;344:1527-35.

I8. Lidegaard O, Edstrom B, Kreiner S. Oral contraceptives and venous thromboembolism: a five-year national case-control study. Contraception 2002;65:187-96.

I9. Collaborative Group on Hormonal Factors in Breast Cancer. Breast cancer and hormonal contraceptives: collaborative reanalysis of individual data on 53297 women with breast cancer and Ioo 239 women without breast cancer from 54 epidemiological studies. Lancet 1996 ; 347 :1713-27

20. Oral-contraceptive use and the risk of breast cancer. The Cancer and Steroid Hormone Study of the Centers for Disease Control and the National Institute of Child Health and Human Development. N Engl J Med I986;315:405-II.

2I. Marchbanks PA, McDoanld JA, Wilson HG, et al. Oral contraceptives and the risk of breast cancer. N Engl J Med 2002;346:2025-32.

22. Gallo MF, Lopez LM, Grimes DA, et al. Combination contraceptives: effect on weight. Cochrane Database Syst Rev 2006; (I):CDoo3987.

23. Sibai BM, Odlind V, Neador ML, et al. A comparative and pooled analysis of the safety and tolerability of the contraceptive patch. Fertil Steril 2002;77:Sig-26.

24. Roumen FJ, Apter D, Mulders TM, et al. Efficacy, tolerability and acceptability of a novel contraceptive vaginal ring releasing etonogestrel and ethinyl oestradiol Hum Reprod 200I;16:469-75.

25. Alexander NJ, Haring T, Mulders TM. A pharmacokinetic interaction study of NuvaRing and a vaginally administered spermicide or antimycotic. Fertil Steril 2002;78:S24-5.

26. Dieben TO, Roumen FJ, Apter D. Efficacy, cycle control, and user acceptability of a novel combined contraceptive vaginal ring. Obstet Gynecol 2002;100:585-93.

27. Scholes D, Lacroix AZ, Ickikawa LE, et al. Change in bone mineral density among adolescent women using and discontinuing depot medroxyprogesterone acetate contraception. Arch Pediatr Adolesc Med 2005;159:139-44.

28. Clark MK, Sowers MR, Nichols S, et al. Bone mineral density changes over two years in first-time users of depot medroxyprogesterone acetate. Fertil Steril 2004;82:1580-6.

29. Cromer BA, Stager M, Bonny A, et al. Depot-medroxyprogesterone acetate, oral contraceptives and bone mineral density in a cohort of adolescent girls. J Adolesc Health 2004;35:434-4I.

30. Scholes D, Lacroix AZ, Ichikawa LE, et al. Injectable hormone contraception and bone density: results from a prospective study. Epidemiology 2002;13:58I-7.

31. US Food and Drug Administration. Black box warning added concerning long term use of Depo-Provera Contraceptive Injection [FDA talk paper]. Rockville (MD): FDA; 2004 Nov I7. Available: www.fda.gov/bbs/topics/ANSWERS/2004 /ANSor325.html (accessed 2006 Dec I2).

32. Health Canada, Health Products and Food Branch. Important safety update: potentia effect of Depo-Provera (medroxyprogesterone acetate injectable suspension, USP) on bone mineral density (BMD) changes in adults and adolescents. Ottawa: Health Canada; 2005 June 30. Available: www.hc-sc.gc.ca/dhp-mps/medeff/advisories-avis /prof/2005/depo-provera_2_hpc-cps_e.html (accessed 2006 Dec I2).

33. World Health Organization. WHO statement on hormonal contraception and bone health. Geneva: WHO; 2005. Available: www.who.int/reproductive-health ffamily_planning/bone_health.html (accessed 2006 Dec I2).

34. Black A, Ad Hoc DMPA Committee of the Society of Obstetricians and Gynaecologists of Canada. Canadian contraception consensus: update on depot medroxyprogesterone acetate (DMPA). J Obstet Gynaecol Can 2006;28:305-I3

35. Videla-Rivero L, Etchepareborda JJ, Kesseru E. Early chorionic activity in women bearing inert IUD, copper IUD, and levonorgestrel releasing IUD. Contraception I987;36:217-26

36. Andersson K, Odlind V, Rybo G. Levonorgestrel-releasing and copper-releasing (Nova-T) IUDs during five years of use: a randomized comparative trial. Contraception I994;49:56-72.

37. Benshushan A, Paltiel O, Rojansky N, et al. IUD use and the risk of endometrial cancer. Eur J Obstet Gynecol Reprod Biol 2002;105:166-9.

38. Farley TM, Rosenberg MJ, Rowe PJ, et al. Intrauterine devices and pelvic inflammatory disease: an international perspective. Lancet $1992 ; 339: 785-8$.

39. Lee NC, Rubin GL, Ory HW, et al. Type of intrauterine device and the risk of pelvic inflammatory disease. Obstet Gynecol I983;62:I-6.

40. Hubacher D, Lara-Ricalde R, Taylor DJ, et al. Use of copper intrauterine devices and the risk of tubal infertility among nulligravid women. N EngI J Med 200I;345:56I-7.

4I. Lethaby AE, Cooke I, Rees M. Progesterone or progestogen-releasing intrauterine systems for heavy menstrual bleeding. Cochrane Database Syst Rev 2005;(4):CDoo2I 26.

42. World Health Organization. Improving access to quality care in family planning: medical eligibility criteria for contraceptive use. 3 rd ed. Geneva: WHO; 2004

43. Redmond G, Godwin AJ, Olson W, et al. Use of placebo controls in an oral contraceptive trial: methodological issues and adverse event incidence. Contraception I999;60:8I-5.

44. Westhoff C, Kerns J, Morroni C, et al. Quick Start: a novel oral contraceptive initiation method. Contraception 2002;66:I4I-5.

45. Westhoff C, Morroni C, Kerns J, et al. Bleeding patterns after immediate vs. conventional oral contraceptive initiation: a randomized, controlled trial. Fertil Steril 2003;79:322-9.

46. US Food and Drug Administration. Fertility and Maternal Health Drugs Advisory Committee [meeting transcript]. Washington (DC): US Department of Health and Human Services; I993 May 20.

47. Miller L, Hughes JP. Continuous combination oral contraceptive pills to eliminate withdrawal bleeding: a randomized trial. Obstet Gynecol 2003;101:653-6r.

48. Sulak PJ. Prospective analysis of occurrence and management of breakthrough bleeding during an extended oral contraceptive regimen. Am J Obstet Gynecol 2006;I95:935-4I.

49. Anderson FD, Gibbons W, Portman D. Long-term safety of an extended-cycle oral contraceptive (Seasonale): a 2-year multicenter open-label extension trial. Am Obstet Gynecol 2006;195:92-6.

50. Edleman AB, Gallo MF, Jensen JT, et al. Continuous or extended cycle vs. cyclic use of combined oral contraceptives for contraception. Cochrane Database Syst Rev 2005; (3):CDoo4695.

5I. US Food and Drug Administration. FDA updates labeling for Ortho Evra Contraceptive Patch [press release]. Rockville (MD): FDA; 2005 Nov Io. Available: www .fda.gov/bbs/topics/news/2005/NEWoI262.html (accessed 2006 June 29).

52. Repchinsky C, editor. Compendium of pharmaceuticals and specialties: the Canadian reference for health care professionals. Ottawa: Canadian Pharmacists Association; 2005 .

53. Stewart FH, Kaunitz AM, LaGuardia KD, et al. Extended use of transdermal norelgestromin/ethinyl estradiol: a randomized trial. Obstet Gynecol 2005;105:1389-96.

54. Miller L, Verhoeven CHJ, Hout J. Extended regimens of the contraceptive vaginal ring: a randomized trial. Obstet Gynecol 2005;106:473-82.

55. Grimes DA, Schulz KF. Antibiotic prophylaxis for intrauterine contraceptive device insertion. Cochrane Database Syst Rev 2001;(2):CDoor327.

56. Ellertson C, Evans M, Ferden S, et al. Extending the time limit for starting the Yuzpe regimen of emergency contraception to I20 hours. Obstet Gynecol 2003;I0I:II68-7I.

57. Rodrigues I, Grou F, Joly J. Effectiveness of emergency contraceptive pills between 72 and I20 hours after unprotected sexual intercourse. Am J Obstet Gynecol 200I; I84:53I-7.

58. Ngai SW, Fan S, Li S, et al. A randomized trial to compare 24 h versus I2 h double dose regimen of levonorgestrel for emergency contraception. Hum Reprod 2005;20:307-II.

59. Von Hertzen H, Piaggio G, Ding J, et al. WHO research group on post-ovulatory methods of fertility regulation. Low dose mifepristone and two regimens of levonorgestrel for emergency contraception: a WHO multicentre randomised trial. Lancet 2002;360:1803-10.

6o. Croxatto HB, Devoto L, Durand M, et al. Mechanism of action of hormonal preparations used for emergency contraception: a review of the literature. Contraception 200I;63:III-2I.

6I. Byrne D, Kelley K, Fisher WA. Unwanted teenage pregnancies: Incidence, interpretation, intervention. Appl Prev Psychol 1993;2:IOI-I3.

62. Rollnick S, Mason P, Butler C. Health behaviour change. A guide for practitioners Edinburgh: Churchill Livingtone; I999.

63. Fisher JD, Fisher WA, Cornman DH, et al. Clinician-delivered intervention during routine clinical care reduces unprotected sexual behavior among HIV-infected patients. J Acquir Immune Defic Syndr 2006;4I:44-52.

64. Public Health Agency of Canada. Canadian guidelines on sexually transmitted in fections, 2006 edition. Ottawa: The Agency; 2006. Available: www.phac-aspc.gc.ca /std-mts/sti_2006/pdf/sti2006_e.pdf (accessed 2007 Jan 29).

Correspondence to: Dr. William A. Fisher, Departments of Psychology and of Obstetrics and Gynaecology, Rm. 6430, Social Science Centre, University of Western Ontario, London ON N6A 5C2; fax 51966I-4139; fisher@uwo.ca 